\title{
Relationship between Sedentary Lifestyle and Erectile Dysfunction
}

\author{
Francisco Pedro Pinheiro1 , Aline Cristine Salum Fernandes \\ Maia1, José Germano Ferraz de Arruda2 ${ }^{2}$, Luis César Fava \\ Spessoto², Pedro Francisco Ferraz de Arruda², Fernando Nestor \\ Fácio Júnior ${ }^{2}$
}

\begin{abstract}
${ }^{1}$ Masters Student of the Health Sciences course of the Medicine School in São José do Rio Preto (FAMERP), São José do Rio Preto, SP, Brazil

${ }^{2}$ Department of Urology of the Medicine School in São José do Rio Preto (FAMERP), São José do Rio Preto, SP, Brazil
\end{abstract}

\begin{abstract}
The comfort of modern life causes two important side effects: physical inactivity and obesity. The current lifestyle is strongly influenced by sedentary behavior with a possible effect on sexual activity. The objective of this research was to investigate the association between erectile dysfunction (ED) and physical inactivity, considering: a) the clinical characterization of patients; b) an evaluation of the level of physical activity and c) a possible correlation between ED and physical activity. We prospectively studied 50 patients with ED treated between August 2014 and February 2015. The analysis of the association between the degree of ED (moderate and severe) and qualitative variables (diabetes, alcoholism, smoking and physical activity) was investigated using Pearson's chi-square test. Contrary to our initial expectations, the results show that 38 participants (76\%) presented ED even though they were physically active and thus regular physical activity did not prevent ED. These results do not explain why so many active seniors had ED but perhaps the sample size was too small to arrive at conclusive data.
\end{abstract}

Keywords: Physical Activity, Erectile Dysfunction, Human Health, Sedentary Lifestyle

\begin{abstract}
Introduction
The comfort of modern life causes two important side effects: physical inactivity and obesity. The current lifestyle is strongly influenced by sedentary behavior (Souza \& Oliveira, 2008). In the past, energy was spent doing laundry, mowing grass, carrying objects and plowing. However, nowadays, most daily activities, such as watching television, using a computer and driving a car, use little energy (Pereira et al., 2003).
\end{abstract}

The less physical activity practiced, the more an individual becomes sedentary and the greater the degree of inactivity in the population, the higher overweight and obesity rates become (Pereira et al., 2003). In addition to sporting activities (walking, running, cycling, swimming, aerobics, football), energy is spent in everyday activities such as gardening, parking the car further away to increase the walking distance, walking to the bakery near home, taking the dog for a walk, getting up to change the TV channels, and exchanging using the elevator for walking up the stairs etc.

A sedentary lifestyle is a risk factor for erectile dysfunction (ED), defined as persistent total or partial inability to initiate and/or maintain an erection sufficient to penetrate and complete intercourse until ejaculation (Cavalcanti \& Cavalcanti, 2006). It is not an sporadic event, but one that recurs; it can start suddenly or progressively and can manifest at different degrees (Cavalcanti \& Cavalcanti, 2006).

Studies show that only $10-15 \%$ of affected men seek treatment for ED, possibly because of embarrassment or lack of knowledge about effective treatment options (Barros, 2000). This can lead some to consider the possibility of suicide, because they consider ED a problem of their masculinity (Figueiredo \& Schraiber, 2011). In addition to

This article is published under the terms of the Creative Commons Attribution License 4.0 Author(s) retain the copyright of this article. Publication rights with Alkhaer Publications. Published at: http://www.ijsciences.com/pub/issue/2015-12/

DOI: $10.18483 / \mathrm{ijSci} .881$; Online ISSN: 2305-3925; Print ISSN: 2410-4477 
negatively affecting the individual's self-esteem, dysfunction can have serious consequences on other aspects of the subject such as anxiety and social isolation, as well as losses in interpersonal, family and work relationships (Porst et al., 2013; Phé \& Rouprêt, 2012).

ED is considered a public health problem because it is associated with factors including age, heart disease, hypertension, diabetes, and hyperlipidemia, but it can be related to an individual's lifestyle such as physical inactivity, obesity, smoking and alcohol abuse (Efremov et al., 2015; Ramirez et al., 2015).

ED is closely linked to the general state of the individual's physical and psychological wellbeing (Efremov et al., 2015) and there are even indications that ED may be an early marker of depression (Grant et al., 2013).

In 40 - to 70 -year-old men, the incidence of $\mathrm{ED}$ is $46 \%$ in Italy, $48 \%$ in Brazil, $52 \%$ in the United States and $54 \%$ in Japan. Regarding the presence of other diseases, the frequency is $33 \%$ in individuals with high cholesterol, $46 \%$ in hypertensive subjects, $75 \%$ in diabetic patients and $90 \%$ in depressed men (Berg, 2004). Worldwide, ED affects more than 100 million men (Ramirez et al., 2015).

Sedentary individuals present ED rates between 43 and $70 \%$, however, according to the literature, regular physical activity reduces the risk of ED by one-third (Li \& Siegrist, 2012). In subjects with ED, it is estimated that 60 minutes of exercise a day, 3 to 4 days per week using $70-80 \%$ of maximum aerobic capacity can increase the frequency of intercourse, and improve erectile function and regulation of testosterone levels (Li \& Siegrist, 2012). In addition, regular exercise reduces the risk of acute myocardial infarction during sexual intercourse (Gorge et al., 2003).

A sedentary lifestyle harms the body; besides being associated to obesity, it is a risk factor for diseases including ED. On the other hand, physical exercise can contribute effectively to the recovery, maintenance, and promotion of health thereby improving the quality of life of the individual with ED.

Thus, research that assesses the impact of a sedentary lifestyle on individuals with ED is needed. The objective of this study was to investigate the association between ED and physical inactivity, considering the clinical and demographic characteristics of patients with ED, thus evaluating the association between ED and the level of physical activity.

\section{Patients and Methods}

Fifty patients with ED, regardless of race, with ages ranging from 38-79 years (mean: $57.7 \pm 8.8$ years) from the region of São José do Rio Preto, Brazil were prospectively studied. These individuals were evaluated from August 2014 to February 2015. This study was approved by the Research Ethics Committee of FAMERP, and patients were only enrolled after being informed about the purpose and the importance of the study, and after signing informed consent forms.

The inclusion criterion was patients with ED diagnosed more than six months previously who were already under treatment irrespectively of whether they were sedentary or not. The exclusion criteria were an inactive sex life, age under 18 years, morbid obesity and physical disabilities.

The international Index of Erectile Function (IIEF-5) was used to determine the degree of ED. The summed scores are grouped as follows: from 17 to 24 indicates individuals with mild ED; scores between 10 and 16 indicate patients with moderate ED and scores of less than 10 identified subjects with severe ED (Rosen et al., 1999; Rosen et al., 1997).

The International Physical Activity Questionnaire IPAQ was used to measure the physical activity (Matsudo et al., 2001). This questionnaire assesses the time and intensity of physical activity performed by the individual over one week. The IPAQ evaluates the level of physical activity during work, travelling, and leisure and sporting activities and of sitting. The level of physical activity was classified as follows: a) physically active individuals performed at least 150 minutes of activities per week on at least five days; $b$ ) insufficiently active individuals practiced physical activity for at least 10 continuous minutes per week c) sedentary individuals did not perform physical activity for at least 10 continuous minutes per week.

The final scores of the physical activity questionnaire were obtained from the sum of the different dimensions (work, transportation, domestic tasks, leisure and sports).

A G-Tech digital weighing scales and Wiso tape measure were used to measure and calculate anthropometric indicators (weight, height, body mass index (BMI), waist, hip, waist-hip ratio, body fat percentage, percentage of hydration, percentage of muscles, percentage of bone mass).

Descriptive statistics (mean, standard deviation, minimum and maximum) were used in the data analysis. Quantitative variables were compared using the t-test for two independent samples. The analysis of any possible association between the degree of ED (moderate and severe) and qualitative variables 
(diabetes, alcoholism, smoking, physical activity) was achieved using Pearson's chi-square test. Analyses of risk assessment with results as odds ratios (OR) were performed using binary logistic regression. All analyzes were performed using the R64 computer software version 2.13.0 (The R Foundation for Statistical Computing, Auckland, New Zealand). The level of significance was set for an $\alpha$ error greater than $5 \%$.

\section{Results}

Twenty-one $(42 \%)$ of the patients studied $(\mathrm{n}=50)$ had moderate ED (Grade 2) and 29 (58\%) had severe ED (Grade 3).

Of the 50 participants, $12(24 \%)$ were aged between 38 and 49 years, $19(38 \%)$ between 50 and 59 years, $13(26 \%)$ between 60 and 69 years and six (12\%) between 70 and 79 years.

The BMIs of under 60-year-old participants were as follows: seven $(22.5 \%)$ had normal weights (10.5- $\left.24.9 \mathrm{~kg} / \mathrm{m}^{2}\right)$, four $(12.9 \%)$ were overweight $(25.0$ $\left.29.9 \mathrm{~kg} / \mathrm{m}^{2}\right), 15(48.4 \%)$ had Grade 1 obesity (30.0$\left.34.9 \mathrm{~kg} / \mathrm{m}^{2}\right)$, four $(12.9 \%)$ Grade 2 obesity (35.0-39, 9 $\left.\mathrm{kg} / \mathrm{m}^{2}\right)$ and one $(3.3 \%)$ had Grade 3 obesity $(\geq 40$ $\mathrm{kg} / \mathrm{m}^{2}$ ). In over 60 -year-old participants, the results were: one $(5.3 \%)$ was underweight $\left(<22.0 \mathrm{~kg} / \mathrm{m}^{2}\right)$, eight $(42.1 \%)$ had normal weights $\left(22.0-27.0 \mathrm{~kg} / \mathrm{m}^{2}\right)$ and ten $(52.6 \%)$ were overweight $\left(>27.0 \mathrm{~kg} / \mathrm{m}^{2}\right)$.

There was no significant difference between the degrees of ED (grade 2 and 3) in respect to demographic and clinical variables (age, weight, height, BMI, waist, hip and percentages of fat, hydration, muscle and bone mass) (Table 1). The pvalues for the variables percentage of fat and percentage of hydration were close to 0.05 .

Table 1 - Comparison of demographic and clinical variables in relation to grade $2(n=21)$ and $3(n=29)$ erectile dysfunction using the $t$ test for two independent samples.

\begin{tabular}{lllll}
\hline Variable & Degree & Mean & SD & p-value \\
\hline Age (years) & 2 & 55.6 & 8.3 & 0.14 \\
Weight (kg) & 3 & 59.3 & 8.9 & \\
& 2 & 87.2 & 20.1 & 0.59 \\
Height (m) & 3 & 84.3 & 16.7 & \\
& 2 & 1.68 & 0.10 & 0.48 \\
BMI & 3 & 1.70 & 0.08 & \\
& 2 & 30.5 & 4.9 & 0.27 \\
Waist (cm) & 3 & 28.9 & 4.8 & \\
& 2 & 104.1 & 14.5 & 0.60 \\
Hip (cm) & 3 & 102.0 & 13.3 & \\
& 2 & 101.8 & 10.9 & 0.77 \\
Fat (\%) & 3 & 100.9 & 9.9 & \\
& 2 & 30.4 & 7.1 & 0.07 \\
Hydration (\%) & 3 & 26.7 & 6.3 & \\
& 2 & 47.8 & 4.9 & 0.06 \\
Muscles (\%) & 3 & 50.3 & 4.3 & \\
\multirow{2}{*}{ Bone mass (\%) } & 2 & 35.8 & 3.5 & 0.11 \\
& 3 & 37.4 & 2.8 & \\
& 3 & 12.0 & 0.9 & 0.93 \\
\hline
\end{tabular}

SD: standard deviation; BMI: body mass index

The study of the relationship between waist-hip ratio and risk to the health of men (Table 2) showed that 36 (72\%) patients with ED are at high risk of developing diseases caused by an excess of abdominal fat.

Table 2 - Waist-hip ratio: risk to health according to age and stratification of patients in current study.

\begin{tabular}{lllllll}
\hline Age (years) & Low risk & $\mathrm{N}$ & Moderate risk & $\mathrm{n}$ & High risk & $\mathrm{n}$ \\
\hline $30-39$ & $<0.84$ & & $0.84-0.91$ & & $0.92-0.96$ & 1 \\
$40-49$ & $<0.88$ & & $0.88-0.95$ & & $0.96-1.00$ & 11 \\
$50-59$ & $<0.90$ & & $0.91-0.98$ & 7 & $0.97-1.02$ & 12 \\
$60-79$ & $<0.91$ & 1 & $0.91-0.98$ & 6 & $0.99-1.03$ & 12 \\
\hline
\end{tabular}

There was no significant association between the degree of ED (grade 2 and 3) and diabetes, smoking and alcohol consumption (Table 3). 
Table 3 - Association of Moderate (2) and severe (3) erectile dysfunction with diabetes, smoking and alcohol consumption.

\begin{tabular}{|c|c|c|c|c|}
\hline ED degree & Diabetic & No Diabetic & Total & $\mathrm{P}$ \\
\hline 2 & 52.4 & 47.6 & 42.0 & \\
\hline 3 & 37.9 & 62.1 & 58.0 & 0.310 \\
\hline Total & 100 & 100 & 100 & \\
\hline ED degree & Smoker & Non-smoker & Total & $\mathrm{P}$ \\
\hline 2 & 25.0 & 45.2 & 42.0 & \\
\hline 3 & 75.0 & 54.8 & 58.0 & 0.288 \\
\hline Total & 100 & 100 & 100 & \\
\hline ED degree & Alcohol drinker & No alcohol drinker & Total & $\mathrm{P}$ \\
\hline 2 & 28.6 & 71.4 & 42.0 & \\
\hline 3 & 41.4 & 58.6 & 58.0 & 0.352 \\
\hline Total & 100 & 100 & 100 & \\
\hline
\end{tabular}

Diabetes: Pearson chi-square $=1.032 ; \mathrm{GL}=1$

Smoking: Pearson chi-square $=1.130 ; \mathrm{GL}=1$

Alcoholism: chi-square $=0.867$ Pearson; $\mathrm{GL}=1$

Regarding the level of physical activity of the participants, 38 (76\%) said they were active, six (12\%) said they were insufficiently active and only six (12\%) reported being sedentary (Table 4$)$.

Table 4 - Degree of erectile dysfunction (ED) in respect to physical activity.

\begin{tabular}{lccc}
\hline Degree of ED & Active & Insufficiently Active & Sedentary \\
& $\mathrm{n}(\%)$ & $\mathrm{n}(\%)$ & $\mathrm{n}(\%)$ \\
\hline 2 & $17(81)$ & $3(14.2)$ & $1(4.8)$ \\
3 & $21(72.5)$ & $3(10.3)$ & $5(17.2)$ \\
Total & $38(76)$ & $6(12)$ & $6(12)$ \\
\hline
\end{tabular}

There was no statistically significant association between the degree of ED (moderate and severe) and physical activity (active, insufficiently active and sedentary) (p-value $=0.272$ ) (Table 5).

Table 5 - Degree of erectile dysfunction (ED) [Moderate (2) and severe (3)] and level of physical activity.

\begin{tabular}{llllll}
\hline Degree of ED & Active & IA & Sedentary & Total & P-value \\
\hline 2 & 80.9 & 14.3 & 4.8 & 42.0 & \\
3 & 69.0 & 10.3 & 20.7 & 58.0 & 0.272 \\
Total & 100 & 100 & 100 & 100 & \\
\hline
\end{tabular}

IA = Insufficiently Active

Pearson chi-square $=2.601 ;$ GL $=2$

\section{Discussion}

Participants of this study presented a high level of physical activity, contrary to our initial expectations. We thought we would find an association between ED and lack of exercise because physical inactivity is considered a high risk factor (Souza et al., 2011). Furthermore, vigorous exercise is associated with a $30 \%$ reduction in risk compared to sedentary individuals or those who do little physical activity (Souza et al., 2011).
However, the results point in the opposite direction. Of the 50 study participants, $38(76 \%)$ presented with ED even though they were physically active. Possibly physiological aging and psychogenic factors, which were not assessed in this study, may have negatively influenced erectile function.

In this research, regular physical activity had no positive impact on male sexual health. This is contrary to what is reported in the medical literature that physical activity may modify or prevent ED 
(Oliveira et al., 2010; Wang et al., 2014; Leoni et al., 2014; Weber et al., 2013). For the individuals analyzed, the systematic practice of exercise did not contribute to any improvement in sexual intercourse. This result was also found by Abdo et al. (2006) in a population study with 2,862 Brazilians. These authors found no statistically significant association between ED and physical inactivity, attributing this to the fact that most sedentary patients are young, and that there was insufficient time for this condition to cause physical harm and therefore ED.

In this series, we could not determine why so many active seniors had ED. Perhaps the sample size was too small for conclusive results. Therefore, it is suggested that more research should be conducted in order to check whether there is an association between sedentary lifestyle and appearance and/or worsening of ED or not.

\section{Conclusion}

Most patients with ED were obese or at least overweight however, the level of physical activity of most was high. This study did not find any significant association between moderate and severe degrees of ED and physical activity (active, insufficiently active and sedentary).

\section{References}

1. Abdo CHN, Oliveira Jr WM, Scanavino MT, Martins FG. Disfunção erétil: resultados do estudo da vida sexual do brasileiro. Rev Assoc Med Bras 2006;52(6):424-9.

2. Barros D. Diagnóstico e tratamento da disfunção erétil ("impotência") de origens orgânica e psicológica. RBM rev bras med 2000;57(6):524-529.

3. Berg OLD. Dados importantes sobre a impotência sexual. 2004. [on-line]. Disponível em: <http://www.saudesexual.med.br/incidencia.html〉. Acesso em: 03 de maio de 2015.

4. Cavalcanti R, Cavalcanti M. Tratamento clínico das inadequações sexuais. 3 ed. São Paulo: Roca, 2006.

5. Efremov EA, Kasatonova EV, Mel'nik JI. Use of sildenafil citrate for treatment of erectile dysfunction of various etiology. Urologia 2015;(2):117-8, 120-1.

6. Figueiredo WS, Schraiber LB. Concepções de gênero de homens usuários e profissionais de saúde de serviços de atenção primária e os possíveis impactos na saúde da população masculina, São Paulo, Brasil. Ciênc saúde coletiva 2011;16(1):935-944.

7. Gorge G, Fluchter S, Kirstein M, Kunz T. Sex, erectile dysfunction, and the heart: a growing problem. Herz 2003;28(4):284-290.

8. Grant P, Jackson G, Baig I, Quin J. Erectile dysfunction in general medicine. Clin Med 2013;13(2):136-40.

9. Leoni LA, Fukushima AR, Rocha LY, Maifrino LB, Rodrigues B. Physical activity on endothelial and erectile dysfunction: a literature review. Aging Male 2014;17(3):125-30.

10. Li J, Siegrist J. Physical activity and risk of cardiovascular disease: a meta-analysis of prospective cohort studies. Int $\mathbf{J}$ Environ Res Public Health 2012;9:391-407.

11. Matsudo S, Araújo T, Matsudo V, Andrade D, Andrade E, Oliveira LC, Braggion G. Questionário Internacional de Atividade Física (IPAQ): estudo de validade e reprodutibilidade no Brasil. Ativ Fís \& Saúde 2001;6(2):518.

12. Oliveira P, Andrade AT, Dórea C. Atividade física pode melhorar a função erétil? Arq H. Ellis 2010;6(2):18-21.
13. Pereira LO, Francischi RP, Lancha Júnior AH. Obesidade: hábitos nutricionais, sedentarismo e resistência à insulina. Arq Bras Endocrinol Metab 2003;47(2):111-127.

14. Phé V, Rouprêt M. Erectile dysfunction and diabetes. Diabetes Metab 2012;38(1):1-13.

15. Porst H, Burnett A, Brock G, Ghanem H, Giuliano F, Glina S, Hellstrom W, Martin-Morales A, Salonia A, Sharlip I. SOP conservative (medical and mechanical) treatment of erectile dysfunction. J Sex Med 2013;10(1):130-71.

16. Ramirez R, Pedro-Botet J, Garcia M, Corbella E, Merino J, Zambón D, et al. Dysfunction and cardiovascular risk factors in a Mediterranean diet cohort. Intern Med J 2015; Oct 20.

17. Rosen RC, Cappelleri JC, Smith MD, Lipsky J, Peña BM. Development and evaluation of an abridged, 5-item version of the International Index of Erectile Function (IIEF-5) as a diagnostic tool for erectile dysfunction. Int J Impot Res 1999;11:319-26.

18. Rosen RC, Riley A, Wagner G, Osterloh IH, Kirkpatrick J, Mishra A. The international index of erectile function (IIEF) a multidimensional scale for assessment of erectile dysfunction. Urology 1997;49:822-30.

19. Souza CA, Cardoso FL, Silveira RA, Wittkopf PG Importância do Exercício Físico no Tratamento da Disfunção Erétil. Rev Bras Cardiol 2011;24(3):180-185.

20. Souza NPP, Oliveira MRM. O ambiente como elemento determinante da obesidade. Rev Simbio-Logias 2008;1(1):157-173.

21. Wang W, Wang JQ, Wan F, Yang L. Physical exercise improves erectile function in young and middle-aged men. Zhonghua Nan Ke Xue 2014;20(12):1086-9.

22. Weber MF, Smith DP, O'Connell DL, Patel MI, de Souza PL Sitas F, et al. Risk factors for erectile dysfunction in a cohort of 108477 Australian men. Med J Aust 2013;199(2):10711. 